\title{
Leucine-Rich Amelogenin Peptide: A Candidate Signaling Molecule During Cementogenesis
}

Fernanda Boabaid, ${ }^{\dagger}$ Carolyn W. Gibson,§ Melissa A. Kuehl,§ Janice E. Berry, ${ }^{\dagger}$ Malcolm L. Snead,॥ Francisco H. Nociti Jr., ${ }^{* \mathbb{I}}$ Eduardo Katchburian, ${ }^{\dagger}$ and Martha J. Somerman*

Background: Cementum is a critical mineralized tissue; however, control of its formation remains undefined. One hypothesis is that enamel matrix proteins/peptides secreted by ameloblasts and/or epithelial rest cells contribute to the control of cementum formation via epithelial-mesenchymal interactions. Here, we focused on determining whether or not leucine-rich amelogenin peptide (LRAP), translated from an alternatively spliced amelogenin RNA, altered cementoblast behavior.

Methods: Immortalized murine cementoblasts (OCCM-30) were exposed to LRAP and evaluated for: 1) proliferative activity; 2) gene expression using Northern blot for Cbfa1 (core binding factor alpha-1); OCN (osteocalcin), OPN (osteopontin), and real-time reverse transcription-polymerase chain reaction (RT-PCR) for OPG (osteoprotegerin); and RANKL (receptor activator of NF$\kappa B$ ligand); 3) signaling pathway using inhibitors of PKA (THFA), PKC (GF109203X), and MAPK (UO126); and 4) mineralization evaluated by von Kossa and Alizarin-red.

Results: LRAP had no effect on cell proliferation up to 6 days, with a decrease in cell growth observed at the highest dose by 9 days versus untreated cells. LRAP down regulated OCN and up regulated OPN in a dose- and time-response fashion, and inhibited the capacity of mineral nodule formation. Transcripts for OPG were increased in LRAP-treated cells compared to control, but RANKL mRNA levels were not affected. Core binding factor alpha (Cbfa) mRNA, expressed constitutively, was not affected by LRAP. Signaling pathway assays suggested involvement of the MAPK pathway, since the addition of the MAPK inhibitor suppressed OPN expression in LRAP-treated cells.

Conclusion: Leucine-rich amelogenin peptide appears to have a direct effect on cementoblast activity that may prove significant during development as well as in regeneration of periodontal tissues. J Periodontol 2004;75:1126-1136.

\section{KEY WORDS}

Cementoblasts; dental cementum; peptides, leucine-rich amelogenin; periodontal regeneration.

* Department of Periodontics, School of Dentistry, University of Washington, Seattle, WA.

$\dagger$ Department of Periodontics/Prevention/Geriatrics, School of Dentistry, University of Michigan, Ann Arbor, MI.

‡ Department of Morphology, School of Medicine, Federal University of São Paulo, São Paulo, SP, Brazil.

$\S$ Department of Anatomy and Cell Biology, University of Pennsylvania School of Dental Medicine, Philadelphia, PA.

|| Center for Craniofacial Molecular Biology, School of Dentistry, University of Southern California, Los Angeles, CA.

Il Department of Periodontics, School of Dentistry at Piracicaba, University of Campinas, Piracicaba, SP, Brazil.

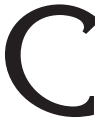
ementum is a unique mineralized tissue covering tooth root surfaces which, in conjunction with the periodontal ligament and alveolar bone, forms the periodontal attachment apparatus, responsible for the maintenance of the tooth within the dental alveolus. Disarrangement in any one of the periodontal components results in instability and loss of a functional dentition. Several studies have focused on the origin of and factors related to cementum formation, both during development and regeneration, ${ }^{1-4}$ yet the cells and factors controlling cementum formation are still elusive.

Epithelial-mesenchymal interactions are required for formation of enamel (ameloblasts) and dentin (odontoblasts) origins, ${ }^{5}$ however, it is less clear whether epithelial-mesenchymal signaling molecules mediate later stages of tooth development, including tooth root and periodontal ligament formation. Several research groups have provided some evidence that enamel matrix proteins may be involved in root formation. ${ }^{6-10}$ In this regard, we reported that amelogenin null mice exhibited reduced expression of bone sialoprotein (BSP) along the tooth root surface (cementoblasts). ${ }^{11,12}$ This reduction of a molecule, considered critical for regulating mineralization, ${ }^{13,14}$ suggests that amelogenin may have a role in regulating genes associated with root formation. In addition, Hatakeyama et al. ${ }^{10}$ found an increased number of osteoclasts and root resorption in developed roots from amelogenin-null mice, 
and they suggested that amelogenins may protect against osteoclastic activity.

Studies to date have identified amelogenin and amelogenin-like molecules secreted by epithelial cells as candidates for interacting with mesenchymal cells within the local area to promote cementum formation. ${ }^{8,9}$ In fact, the major product commercially available for this purpose, a porcine enamel matrix derivative ${ }^{\#}$ (EMD), is considered to be a compound of amelogenins (90\%). ${ }^{15}$ Results from several studies provide evidence that EMD promotes proliferation, migration, adhesion, mineralization, and differentiation of cells associated with periodontal tissues in vitro ${ }^{16-20}$ and periodontal regeneration when applied to denuded root surfaces in dehiscence models in vivo. ${ }^{21}$ More recently, using a fulllength amelogenin [rp(H)M180], Viswanathan et al. ${ }^{12}$ confirmed that amelogenin does alter genes associated with cementoblasts but, unlike EMD, did not alter cell proliferation.

At the molecular level, amelogenins are the expression product of $\mathrm{X}$ and $\mathrm{Y}$ chromosomal genes that give rise to multiple alternatively spliced variants with suggested involvement in a range of activities, including mineral nodule formation and intercellular signaling. ${ }^{22}$ One of these alternative spliced products is a leucine-rich amelogenin peptide LRAP, which is translated from a shorter mRNA that has the coding regions from exons 4,5 , and part of 6 deleted during splicing. This peptide has also been designated as [A-4] to emphasize the absence of the amino acid sequence translated from amelogenin exon 4. ${ }^{23,24}$ LRAP molecules have been demonstrated to increase the expression of certain bone-specific markers, with a suggestion that LRAPs act as signaling molecules for promoting epithelial (ameloblast)-mesenchymal (odontoblast) interactions. ${ }^{24,25}$

Based on the existing research data suggesting that LRAPs may serve as an epithelial-mesenchymal signaling molecule, we focused on determining whether LRAP influenced cementoblast activity, including expression of genes associated with cell differentiation, maturation, mineralization, and osteoclast activation. As described below, our results demonstrated that cementoblasts exposed to LRAP in vitro exhibit increased expression of osteopontin (OPN) and osteoprotegerin (OPG), decreased expression of osteocalcin (OCN), and decreased mineral formation without altering cell proliferation when compared to untreated cells.

\section{MATERIALS AND METHODS}

\section{Cell Culture}

Murine cementoblasts were used in this study. Briefly, as described by D'Errico et al., ${ }^{26}$ immortalized cementoblasts were obtained from the root surface of first mandibular molars of OC-T-Ag transgenic mice ${ }^{27}$ obtained from Dr. Jolene Windle (Virginia Commonwealth University, Richmond, Virginia). These mice contain the SV40 large $\mathrm{T}$-antigen (T-Ag) under control of the osteocalcin (OCN) promoter. Only cells that express OCN also express T-Ag and are immortalized in vitro. OCN is expressed by cementoblasts during root development, but not by cells within the PDL (periodontal ligament cells). Consequently, when cell populations are isolated from developing molars using collagenase/trypsin digestion, only cementoblasts, not PDL cells, are immortalized and thus survive in culture. This immortalized cell line has been well characterized, and results from existing studies indicate that these cells maintain an "osteoblast/ cementoblast" phenotype in vitro and behave in a similar fashion to primary cementoblast cultures. ${ }^{26,28} \mathrm{Nev}$ ertheless, caution must be used with interpretation of data when using cell lines and, in particular, immortalized cell lines since certain cell behaviors will be modified as a result of the immortalization procedure.

Cementoblasts, designated OCCM-30, were maintained in Dulbecco's modified Eagle's medium (DMEM)** plus $10 \%$ fetal bovine serum (FBS)** containing $100 \mathrm{U} / \mathrm{ml}$ of penicillin** and $100 \mu \mathrm{g} / \mathrm{ml}$ of streptomycin** in a humidified atmosphere of $5 \% \mathrm{CO}_{2}$ at $37^{\circ} \mathrm{C}$.

The LRAP used in these experiments was provided by Dr. Carolyn Gibson (University of Pennsylvania, Philadelphia, Pennsylvania). Porcine LRAP cDNA (a gift from J. Simmer, University of Michigan, Ann Arbor, Michigan) was amplified by polymerase chain reaction (PCR) from a cloning vector, using oligomers that added restriction sites for ligation to pGEX-6P-3 in the proper reading frame. DNA sequence was verified. Protein expression was induced in E. coli using IPTG, and fusion protein was purified using glutathione sepharose $4 \mathrm{~B} .{ }^{\dagger \dagger}$ LRAP is prepared in a buffer solution (75 mM HEPES, $150 \mathrm{mM} \mathrm{NaCl}, 10 \mathrm{mM}$ reduced glutathione, $5 \mathrm{mM}$ DTT, $2 \%$ N-octyl glucoside), which was used as the vehicle control for all experiments. In initial studies we determined that LRAP buffer had no effect on cell behavior, i.e., proliferation, mineralization, or gene expression, beyond that observed with control media (media plus serum, antibiotics, and ascorbic acid). Enamel matrix derivative, a mixture of derivative proteins extracted from tooth germs of pigs, was used as a comparison control for LRAP. EMD is composed mainly of amelogenins, constituting about $90 \%$ of the matrix, ${ }^{15}$ while the other $10 \%$ of the non-amelogenin group includes tuft proteins ${ }^{29}$ and tuftelin. ${ }^{30}$ Effects of EMD on cementoblast behavior have been published. ${ }^{18}$

\section{Proliferation Assay}

Cells were seeded in 24 -well plates ${ }^{\ddagger \ddagger}$ in triplicate at a density of 2,000 cells/well in DMEM containing $5 \%$ FBS. After allowing cells to attach overnight, considered day 0 , media were changed to $2 \%$ serum, ascorbic acid

\# Emdogain, Biora AB, Malmo, Sweden.

** Invitrogen, Gaithersburg, MD.

$\dagger \dagger$ Amersham Biosciences, Arlington Heights, IL.

㭋 Falcon, Becton Dickinson, Franklin Lakes, NJ. 
$(50 \mu \mathrm{g} / \mathrm{ml})$, with the addition of vehicle (control), LRAP $(0.02,0.2$, and $2.0 \mu \mathrm{g} / \mathrm{ml})$ or EMD $(100 \mu \mathrm{g} / \mathrm{ml})$. Media were changed on days 2,5 , and 8 . Cells were harvested with trypsin/EDTA and counted§§ on days 3, 6, and 9. Results were expressed as number of cells/well. Experiments were performed two times with comparable results.

\section{Northern Blot Analysis}

Total RNA was isolated using RNA extraction reagent** and quantified by spectrophotometer. Six micrograms of total RNA was electrophoresed on $1.2 \%$ agaroseformaldehyde gels, transferred to nylon membranes \|\| and cross-linked. The membranes were hybridized with a labeled cDNA probe. The probes were labeled with $\alpha$ ${ }^{32} \mathrm{P}-\mathrm{dCTP} .{ }^{\dagger \dagger}$ After hybridization and washing, blots were exposed to film. "Tl Blots were subsequently stripped and reprobed with $18 \mathrm{~S}$ rRNA cDNA probe to standardize RNA loading and hybridization efficiency. Blots were quantitatively scanned using an imaging system, ${ }^{\# \#}$ and the signals were normalized by calculating the ratio of signal intensities of the assayed markers versus the internal control 18S rRNA. Probes used for Northern blots were OCN, 400 bp of mouse OCN cDNA in pSP65 $5^{31}$ (obtained from Dr. J. Wozney, Genetic Institute, Cambridge, Massachusetts); osteopontin (OPN), MOP-3 consisting of $1 \mathrm{kB}$ of mouse OPN cDNA in PCR II ${ }^{32}$ (gifts from Dr. M. Young and Dr. L. Fisher, National Institute of Dental and Craniofacial Research, National Institutes of Health, Bethesda, Maryland); and core binding factor $\alpha 1$ /osteoblast-specific factor 2 (Cbfa1/OSF2), mouse Cbfa1 cDNA $^{33}$ (from Dr. G. Karsenty, Baylor College of Medicine, Houston, Texas).

\section{Real-Time PCR}

The effect of LRAP on osteoprotegerin (OPG) (a secreted glycoprotein which acts as a decoy receptor and binds to RANKL) and RANKL (a membrane-associated cytokine and a soluble factor which binds to its receptor activator of NF-Kb [RANK] $)^{34,35}$ expression was quantitatively analyzed by real-time PCR. Cells were exposed to media as described above or plus LRAP $(2.0 \mu \mathrm{g} / \mathrm{ml})$ or EMD $(100 \mu \mathrm{g} / \mathrm{ml})$ for 72 hours followed by RNA extraction.

Reverse transcription. Total RNA was DNase treated*** and $1 \mu \mathrm{g}$ was used for cDNA synthesis. The reaction was carried out using the first-strand of cDNA. ${ }^{\dagger \dagger}$

Primer design. Primers for OPG, RANKL, and amelo-

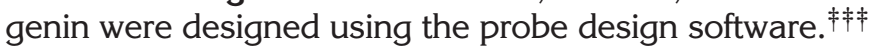
Experiments were run two times with comparable results. Amplification profile was 95/0; 55/7; 72/20 (temperature $\left[{ }^{\circ} \mathrm{C}\right] /$ time $[\mathrm{s}]$ ) and 35 cycles. Primer sequences were as follows: RANKL (CATGACGTTAAGCAACGG/AGG GAAGGGTTGGACA); OPG (TGAATGCCGAGAGTGTAG/ CTGCTCGCTCGATTTG); Amelogenin (TCACTGAG CATACACTCAAAG/GGGTTCGTAACCATAGG).

Optimization of PCR conditions. Reaction efficiency was optimized, and a final concentration of $3 \mathrm{mM} \mathrm{MgCl}$ and $0.5 \mu \mathrm{M}$ primer was chosen.
RT-PCR reactions. RT-PCR was carried out in the light cycler system ${ }^{\neq \neq \dagger}$ using the appropriate kit. ${ }^{\dagger \dagger}$ For each run, water was used as a negative control. Reaction product was quantified using a software program. $\S \S \S$ GAPDH was used as the reference (housekeeping) gene.

\section{Dose-Response Experiment}

Cells were seeded in $60 \mathrm{~mm}$ cell culture dishes at a density of 20,000 cells $/ \mathrm{cm}^{2}$ in DMEM containing $10 \%$ FBS. At confluence, designated day 0 , cells were changed to DMEM containing 5\% FBS and ascorbic acid $(50 \mu \mathrm{g} / \mathrm{ml})$, with vehicle (control), LRAP $(0.02,0.2$, and $2.0 \mu \mathrm{g} / \mathrm{ml})$, or EMD $(100 \mu \mathrm{g} / \mathrm{ml})$. Media were changed at day 2 and total RNA was harvested at 72 hours for OCN and OPN gene expression. Data were standardized relative to $18 \mathrm{~s}$ rRNA, and expressed graphically as percent of control. Experiments were carried out three times with comparable results.

\section{Mineralization Assay}

Cells were seeded in triplicate in 24-well plates at a density of 30,000 cells/well in DMEM containing $10 \%$ FBS. At confluence, designated day 0 , cells were cultured in mineralizing media (DMEM containing 5\% FBS, $50 \mu \mathrm{g} / \mathrm{ml}$ ascorbic acid, and $10 \mathrm{mM} \beta$-glycerophosphate) including vehicle (control), LRAP $(0.02,0.2$, and $2.0 \mu \mathrm{g} / \mathrm{ml})$, or EMD $(100 \mu \mathrm{g} / \mathrm{ml})$. Media were changed every other day and mineral nodule formation determined on day 9 by von Kossa stain for phosphate. Alizarin-red staining and elution was used to quantify $\mathrm{Ca}^{++}$levels expressed as $\mu \mathrm{Mol} \mathrm{Ca}{ }^{++} /$well. Data were evaluated as percent of control and statistical analysis was performed. Results were performed two times with comparable results.

\section{Time Course Experiment}

To determine the temporal effect of LRAP on gene expression, cells were seeded in $60-\mathrm{mm}$ cell culture dishes at a density of 20,000 cells $/ \mathrm{cm}^{2}$ in DMEM containing $10 \%$ FBS. According to the previous findings from our dose-response experiments, LRAP at a dose of $2.0 \mu \mathrm{g} / \mathrm{ml}$ was selected for the time course experiments. At confluence, cells were cultured in DMEM containing $5 \%$ FBS, ascorbic acid $(50 \mu \mathrm{g} / \mathrm{ml})$, with vehicle (control), LRAP $(2.0 \mu \mathrm{g} / \mathrm{ml})$, or EMD $(100 \mu \mathrm{g} / \mathrm{ml})$. Total RNA was extracted at $1,6,12,24$, and 48 hours after treatment. Northern blot analysis was used to determine changes in transcripts for Cbfa1, OPN, and OCN.

\footnotetext{
$\S \S$ Coulter Counter, Beckman-Coulter, Fullerton, CA.

\|l| Strategene, Inc., La Jolla, CA.

II Eastman Kodak Co., Rochester, NY.

\#\# Packard 2024 Instantimager, Perkin Elmer, Boston, MA

$* * *$ DNA-free, Ambion Inc., Austin, TX.

$\dagger \dagger \dagger$ cDNA synthesis kit, Roche Diagnostic Co., Indianapolis, IN.

†キ LightCycler, Roche Diagnostics GmbH, Mannheim, Germany.

$\S \S \S$ LightCycler Relative Quantification Software, Roche Diagnostics GmbH.
} 
Data were standardized relative to $18 \mathrm{~s}$, and expressed graphically as percent of control. Experiments were performed two times with comparable results.

\section{Signal Transduction Pathway}

To identify the signal transduction pathways involved in the regulation of gene expression by LRAP, inhibitors of CAMP-dependent protein kinase $A$ (PKA), protein kinase $C(P K C)$, and MAPK pathways were used. Inhibitors used were as follows: a cell-permeable adenylyl cyclase inhibitor 9-(2-tetrahydrofuryl) adenine

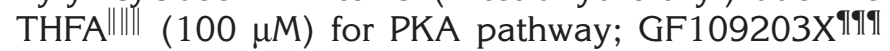
$(3 \mu \mathrm{M})$ for PKC activity and UO126 tft $(20 \mu \mathrm{M})$ for MAPK/MEK-1/2 activity. Vehicle (DMSO) and UO124 (a negative control of UO126) were used as controls. Cells were seeded in 60-mm cell culture dishes at a density of 20,000 cells $/ \mathrm{cm}^{2}$ in DMEM containing $10 \%$ FBS. At confluence, designated day 0 , cells were cultured in DMEM containing 5\% FBS, ascorbic acid $(50 \mu \mathrm{g} / \mathrm{ml})$, and vehicle (control) or $2.0 \mu \mathrm{g} / \mathrm{ml}$ LRAP, for 3 days with medium change on day 2. Inhibitors dissolved in DMSO (used as control) were added on day 2 and RNA extracted on day 3. Northern blot analysis was performed to determine changes in OCN and OPN gene expression. In previous experiments we showed that DMSO alone did not alter the expression of the genes analyzed. Experiments were performed two times with comparable results.

\section{Statistical Analysis}

Data from proliferation, mineralization, and Northern blot assays were analyzed by multiple variance (ANOVA) followed by Student $t$ test. ${ }^{\# \# \# ~ D a t a ~ o b t a i n e d ~ b y ~ r e a l-t i m e ~}$ PCR were analyzed by one way ANOVA at a level of $5 \%$ of significance. If a statistical difference was detected, the Bonferroni $t$ test was used to identify groups that differed from control.

\section{RESULTS}

\section{Effect of LRAP on Cell Proliferation (Fig. 1)}

To determine if LRAP had any toxic effect on cells, and also to determine whether LRAP promoted cell proliferation in a comparable manner reported for EMD, cells were exposed to LRAP or EMD and cell number counted over a 9-day period. Selected doses of LRAP were used to evaluate if effects were dose dependent.

As seen in Figure 1, until day 3 no dramatic changes were observed in cell proliferation regardless of treatment. By day 6 , a significant increase in cell proliferation (2-fold) was seen in EMD treated cells versus control, as expected based on previous studies. ${ }^{18}$ On day 6 , cells treated with LRAP and vehicle (control) had comparable growth patterns. On day 9 the two higher doses of LRAP $(0.2$ and $2.0 \mu \mathrm{g} / \mathrm{ml})$ inhibited cell growth, 1.3-fold and 1.5-fold, respectively, when compared with vehicle control. Morphological

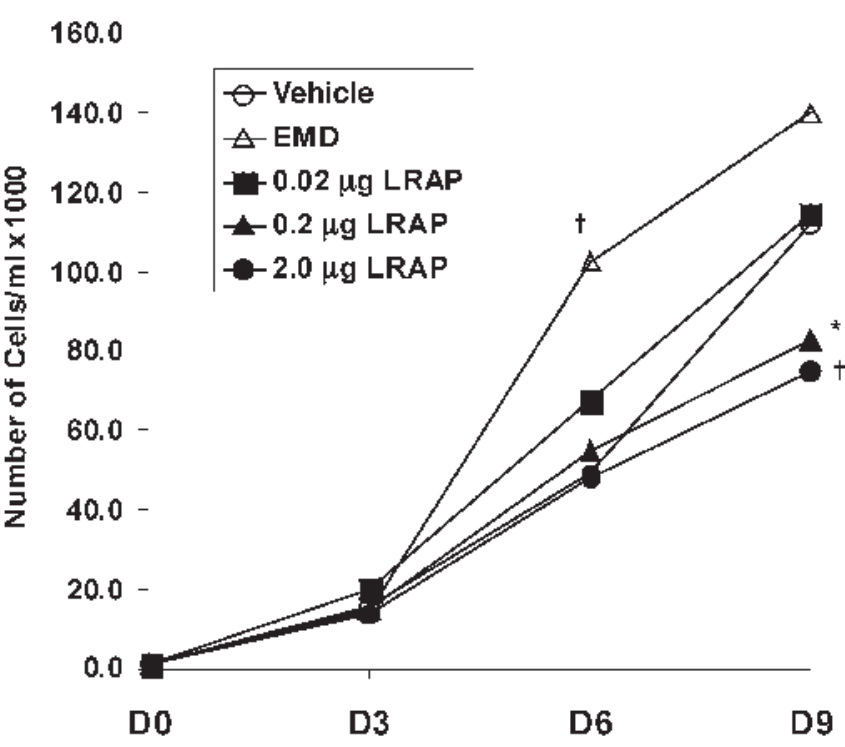

Figure I.

Proliferation assay. Cementoblasts (OCCM cells), cultured in media with $5 \%$ serum and ascorbic acid $(50 \mu \mathrm{g} / \mathrm{ml})$, were treated with vehicle control, LRAP $(0.02,0.2$, and $2.0 \mu \mathrm{g} / \mathrm{ml})$, or EMD $(100 \mu \mathrm{g} / \mathrm{ml})$. Media were replenished on days 2, 5, and 8. Cell counts were measured on days 3, 6, and 9. LRAP at the higher doses (0.2 and $2.0 \mu \mathrm{g} / \mathrm{ml}$ ) significantly inhibited proliferation of cementoblasts compared to vehicle or EMD at day 9. Results were reproduced in two separate experiments. ${ }^{*} P<0.05$; tP $<0.001$ versus vehicle control.

changes from control were not observed with any of the treatments.

These results suggest that LRAP, in contrast to EMD, over time and in a dose-dependent fashion, decreases cell proliferation when compared to untreated cells.

\section{Effect of LRAP on Gene Expression: Dose-Response Northern Blots (Fig. 2)}

Next, the ability of LRAP to alter gene expression was determined. After exposure for 72 hours to LRAP, EMD, or vehicle, changes in OCN and OPN gene expression were evaluated by Northern blot. Results demonstrated that cementoblasts responded to LRAP in a dose-dependent fashion and with distinct differences noted between genes analyzed. Evaluation of OCN transcripts revealed decreasing steady-state levels of OCN with increasing concentrations of LRAP. This finding is similar to that reported previously for $E \mathrm{MD}^{18}$ and reproduced here (Figs. 2A and 2B).

LRAP at the highest dose, $2.0 \mu \mathrm{g} / \mathrm{ml}$, had dramatic effects on both OCN and OPN gene expression and for this reason this concentration of LRAP $(2.0 \mu \mathrm{g} / \mathrm{ml})$ was used for the subsequent experiments on gene expression.

|||| Sigma Corporation, St. Louis, MO.

ๆๆ

\#\#\# Instat 2.0, GraphPad Software, San Diego, CA. 
A
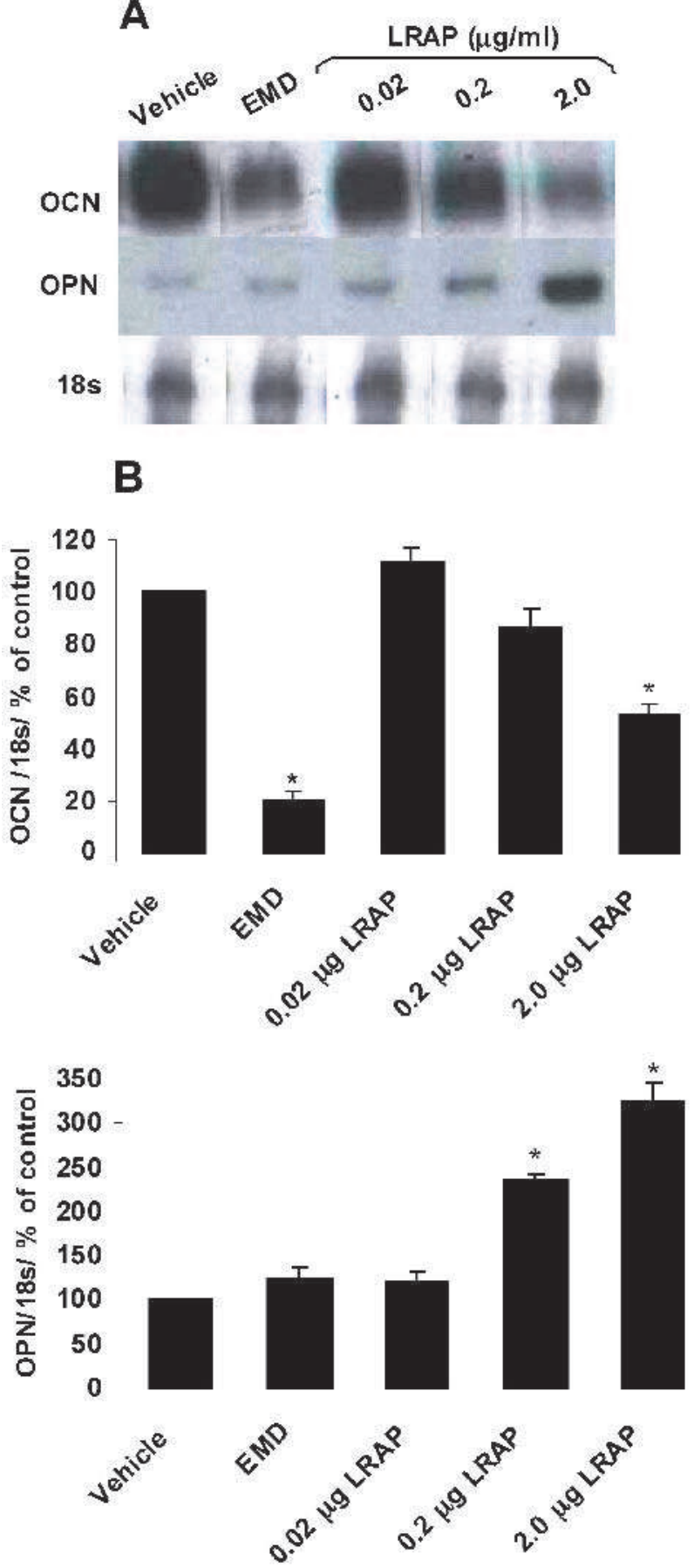

Figure 2.

Dose-dependent effect of LRAP on gene expression by cementoblasts. OCCM cells, cultured in media containing 5\% serum with ascorbic acid (50 $\mu \mathrm{g} / \mathrm{ml})$, were allowed to adhere for 24 hours and then cultured in the same media with vehicle control, LRAP $(0.02,0.2$, and $2.0 \mu \mathrm{g} / \mathrm{ml})$, or EMD ( $100 \mu \mathrm{g} / \mathrm{ml})$. Media were replenished at 48 hours and total RNA extracted at 72 hours. Gene expression for OCN and OPN was analyzed by Northern blot $(\boldsymbol{A})$. Results were normalized for 18s rRNA and expressed graphically as a percentage of the control $(\boldsymbol{B})$. *P $<0.001$ versus vehicle control. Results demonstrated that cementoblasts respond to LRAP in a dose-dependent manner. The highest dose of LRAP (2.0 $\mu g / \mathrm{ml}$ ) promoted significant downregulation of OCN mRNA and upregulation of OPN mRNA. Results were reproduced in three separate experiments.

\section{Effect of LRAP on OPG/RANKL Gene Expression by Real-Time PCR (Fig. 3)}

To determine whether LRAP affected genes known to regulate osteoclast behavior, cells were exposed to vehicle (control), LRAP $(2.0 \mu \mathrm{g} / \mathrm{ml})$, or EMD $(100 \mu \mathrm{g} / \mathrm{ml})$ for 72 hours, RNA was extracted and OPG (osteoprotegerin) and RANKL gene expression quantitatively evaluated by real-time PCR.

In agreement with a recent study, comparing tissues from amelogenin-null mice versus control mice, suggesting a role for amelogenin in regulating the expression of OPG and RANKL, ${ }^{10}$ our findings demonstrate that both LRAP and EMD significantly increase transcripts for OPG (2-fold and 1.5-fold, respectively) compared with vehicle (control) (Fig. 3A). In contrast, RANKL

\section{A}

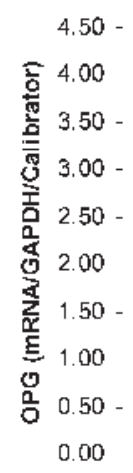

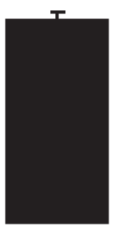

Control

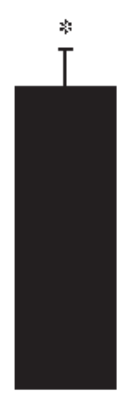

EMD

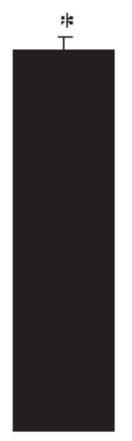

$2.0 \mu \mathrm{g}$ LFAP
B

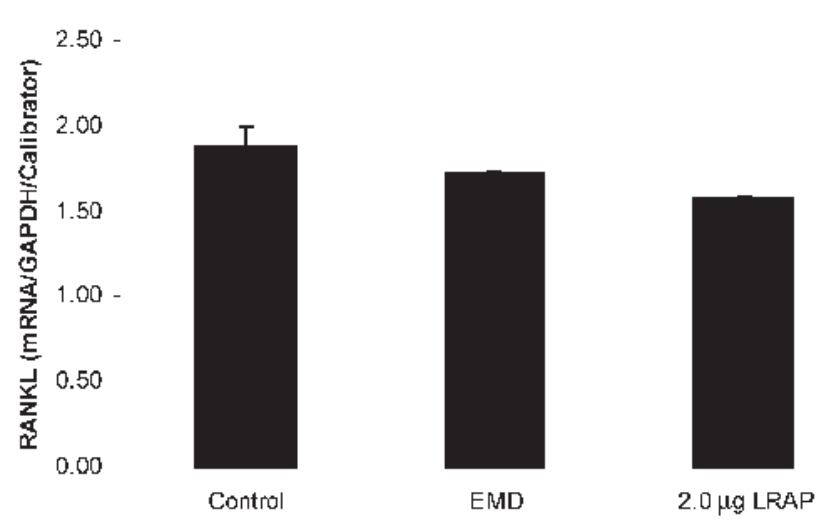

Figure 3.

Real-time PCR for OPG and RANKL. Cementoblasts, cultured in media containing $5 \%$ serum with ascorbic acid $(50 \mu \mathrm{g} / \mathrm{ml})$, were allowed to adhere for 24 hours and then cultured in media containing vehicle control, LRAP $(2.0 \mu \mathrm{g} / \mathrm{ml})$, or EMD ( $100 \mu \mathrm{g} / \mathrm{ml})$. Media were replenished at 48 hours and total RNA extracted at 72 hours. OPG (A) and RANKL (B) expression was quantified by real-time $P C R$. Results were normalized for GAPDH. ${ }^{*} P<0.05$ versus vehicle control. Both LRAP $(2.0 \mu \mathrm{g} / \mathrm{ml})$ and EMD promoted an increase in transcripts for OPG but did not affect RANKL gene expression by cementoblasts. Results were reproduced in two separate experiments. 
mRNA levels were not affected by either LRAP or EMD (Fig. 3B).

\section{Effect of LRAP on Mineralization In Vitro (Fig. 4)}

In agreement with previous results and demonstrated here, cells exposed to EMD ${ }^{18}$ exhibited a decrease in

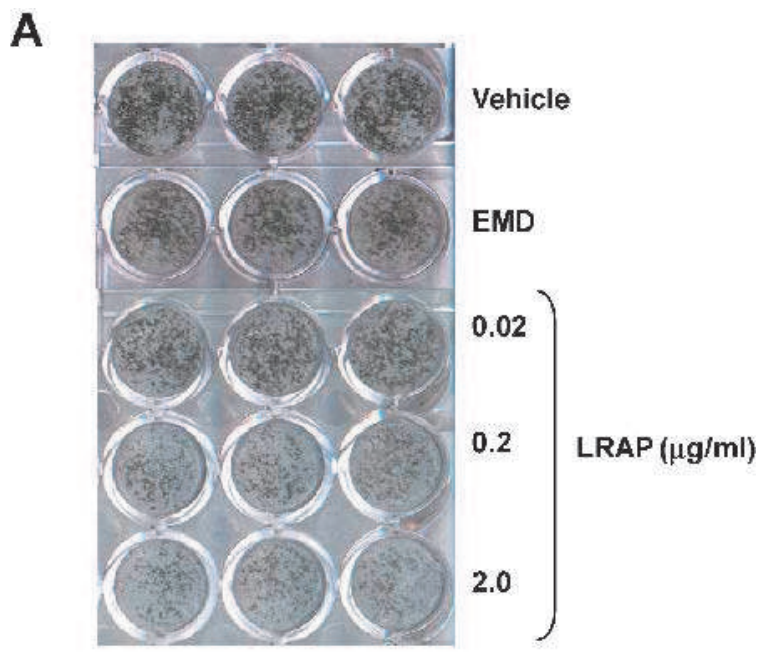

B

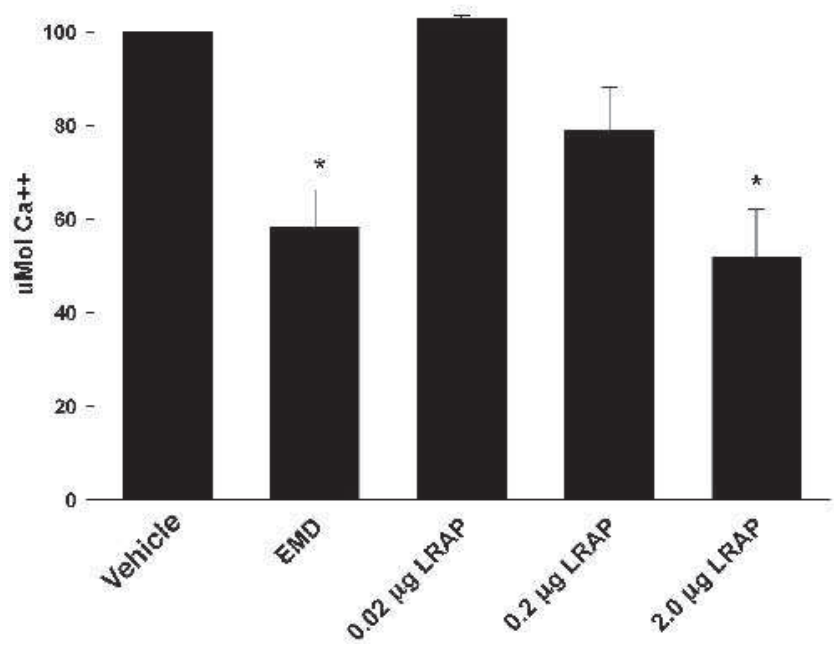

Figure 4.

Mineral nodule formation. Cementoblasts were cultured in mineralization media: media containing 5\% serum, ascorbic acid $(50 \mu \mathrm{g} / \mathrm{ml})$, and $\beta$-glycerophosphate ( $(0 \mathrm{mM})$ with vehicle control, $\operatorname{LRAP}(0.02,0.2,2.0 \mu \mathrm{g} / \mathrm{ml})$, or EMD ( $100 \mu \mathrm{g} / \mathrm{ml})$. Media were changed every other day (day 0 to 8). A) von Kossa staining was performed on day 9 to visualize mineral nodule formation (stain for phosphate). B) Alizarin-red staining and elution were performed for quantification of $\mathrm{Ca}^{++}$levels. Results are expressed as a percentage of the control; *P $<0.05$. A visible decline in mineral formation was noted at all doses of LRAP based on von Kossa stain, but quantification of mineral formation (as measured by $\mathrm{Ca}^{++}$) indicated a significant decline at the highest dose only versus vehicle control. Results were reproduced in two separate experiments. mineral nodule formation, and LRAP had similar effects (Fig. 4). Cementoblasts incubated with increasing doses of LRAP $(0.02,0.2$, and $2.0 \mu \mathrm{g} / \mathrm{ml})$ exhibited a decrease in ability to promote mineralization in vitro. Analysis of mineral nodule formation was performed by von Kossa staining (Fig. 4A), and by quantification for $\mathrm{Ca}^{++}$concentration by Alizarin-red staining and elution (Fig. 4B). Based on the von Kossa assay which stains for phosphate, it appears that LRAP inhibited mineral formation in a dose-response fashion, with the effect noted at all doses. However, when using Alizarin-red for quantification only the highest dose of LRAP $(2.0 \mu \mathrm{g} / \mathrm{ml})$ significantly reduced (1.5-fold) cementoblast-mediated mineralization versus vehicle control, although there did appear to be a dose-response effect.

\section{Effect of LRAP on Gene Expression: Time Course (Fig. 5)}

After demonstrating that LRAP $(2.0 \mu \mathrm{g} / \mathrm{ml})$ had a dramatic effect on OCN and OPN gene expression at 72 hours, the time required for LRAP to alter expression of these genes was evaluated. In time-course experiments, cementoblasts were treated with vehicle (control), LRAP $(2.0 \mu \mathrm{g} / \mathrm{ml})$, or EMD $(100 \mu \mathrm{g} / \mathrm{ml})$ and RNA was extracted at $1,6,12,24$, and 48 hours. Changes in transcripts for Cbfa1, a master switch for cementoblast/osteoblast differentiation, ${ }^{33,36}$ OPN, and OCN were determined by Northern blot analysis (Fig. 5A).

Results of these studies revealed an increase in Cbfa1 mRNA levels in a time-dependent fashion, with no differences in this pattern noted with any treatments, suggesting that neither LRAP nor EMD affect Cbfa1 gene expression (Fig. 5B). For OCN, control cells demonstrated an increase in OCN expression throughout the 24-hour period. Exposure to LRAP resulted in a significant decrease in OCN RNA levels noted by 12 hours. Similarly, EMD also decreased OCN expression by 12 hours (Fig. 5B).

OPN transcripts were upregulated by both LRAP and EMD. LRAP-mediated OPN gene expression was markedly upregulated at 6 hours (4-fold compared to vehicle and 3-fold compared to EMD). This effect was significant and maintained at all time points examined. In parallel, EMD also showed an enhancement in OPN gene expression in comparison to vehicle at 24 hours and 48 hours (Fig. 5A). Although the effect was not dramatic for EMD, it was statistically significant (Fig. 5B) and reproduced in two separate experiments.

\section{Effect of LRAP on Gene Expression: Signal Transduction Pathway (Fig. 6)}

To begin to define the signal transduction pathways involved in LRAP-mediated effects on cementoblasts, specific inhibitors of PKA, PKC, and MAPK were used. The addition of the PKA inhibitor (THFA) did not change OCN or OPN gene expression in vehicle treated 
A

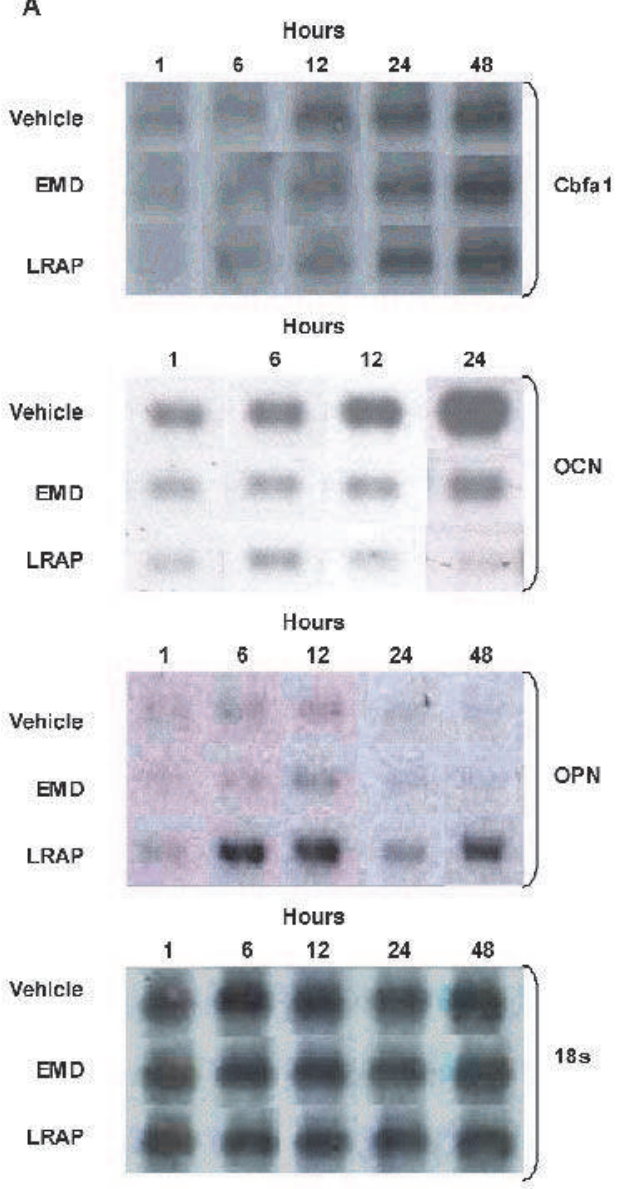

B
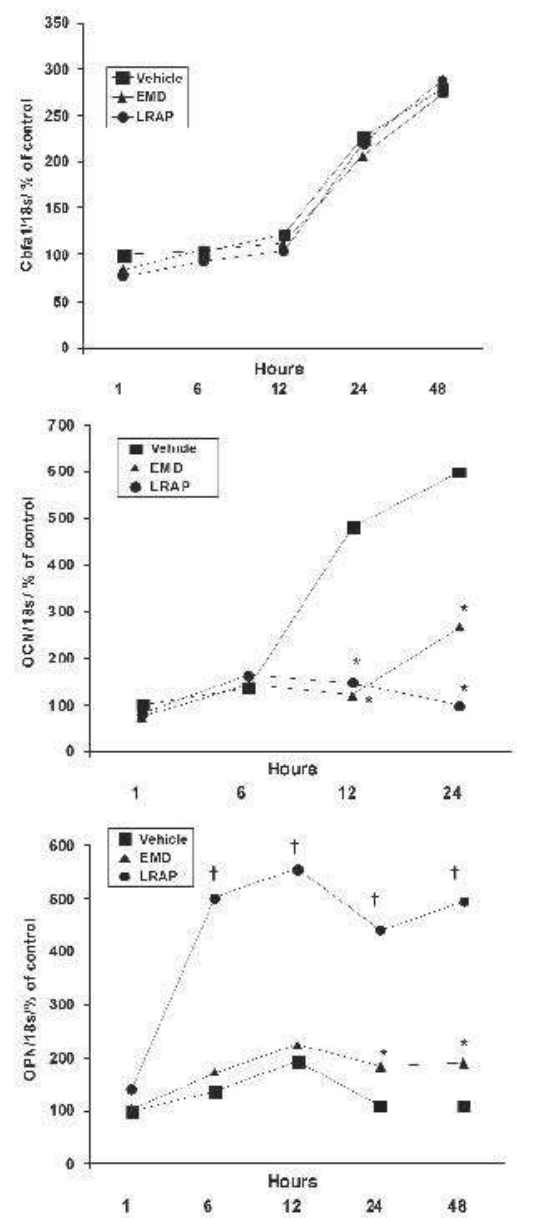

way resulting in further downregulation of OCN (Fig. 6A). In a reverse fashion, it appears that OPN mRNA levels are activated through the MAPK pathway (MEK-1/2) since the MEK-1/2 inhibitor blocked LRAPmediated increased expression of OPN (Fig. 6B).

\section{DISCUSSION}

It is well established that epithelialmesenchymal interactions are required for tooth organogenesis (formation of enamel and dentin) $;^{5}$ however, the mechanisms and cells regulating cementum-periodontal formation remain undefined. Amelogenin isoforms translated from alternatively spliced RNA transcripts have been identified as candidates, potentially serving as signaling molecules during development of the tooth-root and the periodontium. $8,22,25$ In the present study, we focused on determining whether LRAP, a splice variant of the amelogenin RNA transcript, has the ability to alter the behavior of cementoblasts in vitro. The results presented here indicate that cementoblasts in vitro are responsive to LRAP. Analysis of cementoblast gene expression showed that LRAP decreased OCN transcripts and increased OPN mRNA, gene markers associated with the mature osteoblast/cementoblast phenotype ${ }^{38,39}$ and also considered to be regulators of crystal growth. ${ }^{13,39,40}$ Further, our results suggest that LRAP acts as a signaling molecule and may mediate its effects in part through the MAPK pathway.

Results from previous studies suggest that products secreted by tooth-associated epithelial cells; i.e., ameloblasts and HERS cells, promote proliferation of mesenchymal cells, thus providing a critical mass of cells required for promoting formation of mineralized tissues such as tooth root cementum and alveolar bone during both development and regeneration. ${ }^{18,19,41,42}$ In addition, such products may also regulate the extent of mineral formation and allow for development of a periodontal ligament. Tokyiasu et al. ${ }^{18}$ and Hakki et al. ${ }^{19}$ demonstrated that enamel matrix derivative proteins increased cell proliferation but decreased cell-mediated mineral nodule formation in both cementoblasts and 


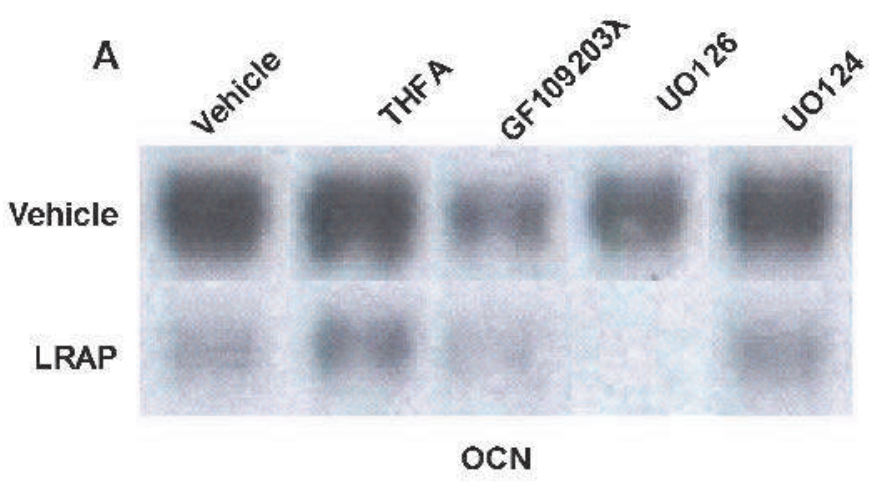

B
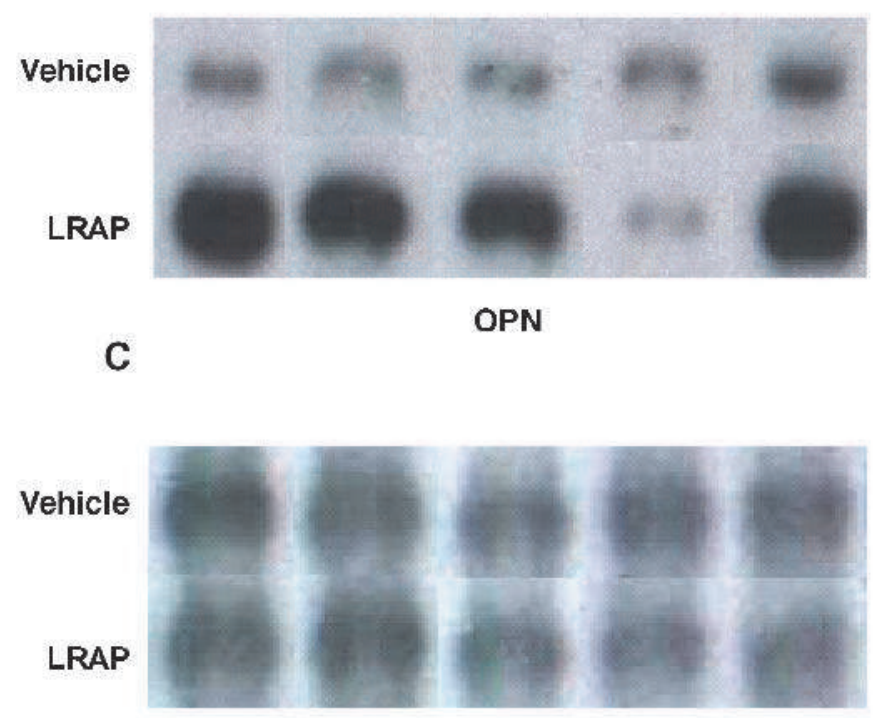

$18 s$

Figure 6.

Signal transduction pathways involved in LRAP-mediated effects on OCN and OPN transcription. Cementoblasts cultured in media containing $5 \%$ serum with ascorbic acid $(50 \mu \mathrm{g} / \mathrm{ml})$ were treated with LRAP $(2.0 \mu \mathrm{g} / \mathrm{ml})$ or vehicle for 72 hours. Media were changed at 48 hours and inhibitors added for 24 hours. Inhibitors used:THFA ( $100 \mu \mathrm{M}$, cAMPIPKA pathway), GFI09203X (3 $\mu \mathrm{M}$, PKC pathway), and UOI 26 (20 $\mu$ M, MAPK pathway). Vehicle (DMSO) and UOI 24 (a negative control of UO I 26) were used as controls. RNA was extracted at 72 hours and expression for OCN (A) and OPN (B) analyzed by Northern blot. I 8s (C) is shown for sample loading comparison. Note that both the PKC and MAPK pathway inhibitors decreased expression of OCN in the vehicle control, suggesting regulation of OCN expression by these pathways. As expected, LRAP decreased OCN expression, with a further decrease noted with both the PKC and MAPK inhibitors. LRAP-mediated enhancement in expression of OPN was prevented in the presence of the MAPK inhibitor. These results suggest that the effect of LRAP on OPN and OCN transcripts is mediated at least in part through the MAPK pathway. Results were reproduced in two separate experiments.

follicle cells in vitro. On the other hand, the full-length amelogenin [rp(H)M180] did not affect cementoblast proliferation at doses from $1 \mu \mathrm{g} / \mathrm{ml}$ up to $10 \mu \mathrm{g} / \mathrm{ml}$, but did inhibit mineral formation versus untreated cells. ${ }^{12}$ Here, we demonstrate that, unlike EMD which increased cell proliferation and amelogenin which had no effect on proliferation, LRAP, at both $0.2 \mu \mathrm{g} / \mathrm{ml}$ and $2.0 \mu \mathrm{g} / \mathrm{ml}$, decreased cell number at day 9 versus vehicle control. The reason for this effect has yet to be addressed, but most likely is related to changes in genes and associated proteins secreted by cementoblasts exposed to LRAP. Further, our data suggest that the ability of EMD to enhance cell proliferation is not due to amelogenin, but rather to other yet to be identified factor(s) within $E M D$, that either directly or indirectly act as growth factors. For example, existing evidence suggests that cells exposed to EMD secrete transforming growth factor $(\text { TGF }-\beta)^{43}$ and that EMD may contain TGF- $\beta$, a molecule capable of stimulating proliferation of gingival fibroblasts. ${ }^{20}$

It is interesting to note that EMD, ${ }^{18}$ full-length amelogenin [rp(H)M180], ${ }^{12}$ and LRAP (Fig. 4) all inhibit cementoblast-mediated mineral nodule formation in vitro, suggesting that amelogenin-like molecules have a role in controlling crystal growth. The ability of amelogenins to regulate crystal growth is well documented and supported by analysis of the structure of enamel in amelogenin null mice. ${ }^{40,44,45}$ Nevertheless, caution must be used in interpreting these results since true "mineralization" was not confirmed by analyzing crystal structure or collagen association in vitro or by any in vivo studies.

In parallel with determining the effects of LRAP on mineral nodule formation, the influence of LRAP on gene expression by cementoblasts was assessed. Studies have demonstrated that leucine-rich amelogenin peptides affect protein expression in the mesenchymal cells, ${ }^{25}$ and specifically influence the expression of BSP. The data presented here showed that LRAP had marked effects on transcripts for OCN, OPN, and OPG. Within the limits of this study, we were not able to demonstrate any changes in BSP mRNA levels (data not shown).

The striking downregulation of OCN gene expression seen with LRAP treatment was also observed in cementoblasts treated with EMD (Fig. 2A) and by Tokiyasu et al. ${ }^{18}$ and with full-length amelogenin protein [rp (H)M180] $(10.0 \mu \mathrm{g} / \mathrm{ml}) .{ }^{12}$ Mineral-related proteins like osteocalcin and osteopontin are expressed by cementoblasts during root development. $26,38,46,47$ OCN is specific to mineralized tissues and is an early marker for cells undergoing mineralization. In addition, there is accumulating evidence that OCN controls crystal growth. ${ }^{48}$ Similarly, EMD, ${ }^{18}$ full-length amelogenin, ${ }^{12}$ and LRAP (Fig. 2B) all promote OPN gene expression by cementoblasts. OPN is found in high concentrations in mineralized tissues and is designated a member of the sibling family, containing RGD cell adhesion domains. ${ }^{49,50}$ With regard to mineralized tissues, sev- 
eral roles have been suggested for OPN, including regulation of crystal growth and migration and attachment of cells to a local site. In examining these results, it is difficult to explain the inhibitory effect on mineral formation as being solely related to these changes; however, the marked increase in OPN expression may counter the abolishment of OCN transcripts and thus results in decreased crystal growth. Alternatively, it is possible that, like amelogenin, LRAP is capable of acting as a nanostructure support or carrier material for other factors (yet to be defined) secreted by cells which are then released by the carrier (LRAP) to regulate cementoblast behavior. Future studies measuring levels of matrix associated proteins in the media will assist in defining the mechanisms by which LRAP controls mineral nodule formation.

Results from studies by Veis et al. ${ }^{23,24}$ have shown that LRAPs upregulate Cbfa1 mRNA levels in embryonic rat muscle fibroblasts. Cbfa1 is considered a master switch for differentiation of bone cells. ${ }^{33,35}$ In contrast, results from our study demonstrated that exposure of cementoblasts to LRAP or EMD did not result in changes in Cbfa1 mRNA levels. This disparity in results compared to those of Veis et al. ${ }^{23}$ are most likely related to differences in cell types used. Cementoblasts are mature cells and thus it is not surprising that expression of Cbfa1, a gene required for cell differentiation rather than maturation, is not altered by LRAP. This finding is supported by results of Lian et al., ${ }^{50}$ in which it was reported that a downregulation or no change in $\mathrm{Cbfa} 1$ gene expression was observed after exposure of mature osteoblasts to specific signaling factors.

In addition to examining changes in genes associated with extracellular matrix formation and crystal growth in cells exposed to LRAP, we also determined whether LRAP alters genes associated with controlling osteoclast activation, OPG and RANKL. The TNF receptor-ligand family members, osteoprotegerin and receptor activator of NF-kB ligand, are produced by osteoblast/stromal cells. RANKL is both a membraneassociated cytokine and a bone microenvironmentassociated soluble factor, and binds to its receptor activator of NF-Kb (RANK) on osteoclast precursor cells to promote osteoclastogenesis. OPG, a secreted glycoprotein, acts as a decoy receptor and binds to RANKL inhibiting osteoclastogenesis. ${ }^{35}$ In the tooth microenvironment, OPG is expressed by follicle cells, ${ }^{51} \mathrm{OPG} /$ RANKL mRNA transcripts are present in human periodontal ligament cells (PDL) in culture ${ }^{52}$ and have been localized in situ by immunohistochemistry in ameloblasts, odontoblasts and dental pulp cells. ${ }^{53}$ As shown in Figure 3A, LRAP and EMD both increased OPG mRNA levels, while having no effect on RANKL expression (Fig. 3B).

Since these experiments only examined mRNA at 72 hours, it is not known if this is a direct effect of
LRAP or related to LRAP's ability to promote other genes/proteins that subsequently alter OPG/RANKL. Such questions will be addressed in the future. Nevertheless, this result is very exciting and suggests that LRAP-cementoblast interactions may act to protect the root surface from osteoclast-mediated root resorption. In support of this, Hatakeyama et al. ${ }^{10}$ reported that amelogenin-null mice exhibited an increase in osteoclasts along the root surface, increased root resorption and increased expression of RANKL in surrounding tissues when compared with appropriate controls.

As shown in Figure 6, results from initial studies targeted at defining the signal pathway(s) controlling LRAP activity implicate involvement of both the PKC and MAPK pathways. While more details are required to confirm these findings, our results parallel those of Kawase et al., ${ }^{20}$ who reported that EMD-induced ERK phosphorylation and p38 MAPK pathways in gingival fibroblastic cells. In those studies, however, Kawase's group concluded that the effect was indirect and related to the presence of TGF- $\beta$. While the results here clearly demonstrate that LRAP affects cementoblast activity in vitro, the relevance of this finding to cementum formation, both during development and regeneration, requires further investigation.

Several groups have provided evidence for the presence of and the ability of enamel proteins, mainly amelogenin and its alternative spliced products, but also laminin, ${ }^{54}$ amelin (ameloblastin, sheathlin), 7,55,56 and other enamel and enamel-like products $6,57,58$ to influence root formation and periodontal development. However, contradictory results have been reported, and to date no group has provided definitive proof that epithelial-derived molecules are involved in tooth root/periodontal tissue development. For example, Hasegawa et al. ${ }^{42}$ showed that enamel proteins, including ameloblastin, are detected in HERS during initial phases of root formation in rats, while Fukae et al..$^{9}$ demonstrated the presence of amelogenin and enamelin on formed root surfaces of porcine permanent incisors. Data from other groups demonstrated that such proteins as ameloblastin are restricted to the crown enamel and absent from surrounding tissues. ${ }^{59}$ In other investigations by Bosshardt and Nanci ${ }^{46}$ and separately by Diekwisch, ${ }^{60}$ it was reported that protein extracts from cementum or cells which secrete the first matrix layer deposited against root surface do not cross-react with amelogenin antibodies in rats and humans, respectively. Similar to these findings, using real-time RT-PCR we were not able to detect the presence of amelogenin mRNA in murine cementoblasts, nor were we able to detect amelogenin in the tooth root/periodontium of developing murine molars by in situ hybridization (data not shown). These contradictory findings may be due to differences in species and/or probes used, as well as the reported significance of low level expression in 
certain tissues versus non-specific results. Additional studies to examine whether differences in effects of LRAP on cells are noted with pulsatile versus continuous delivery should prove valuable. This is an interesting question since it is now recognized that many factors have both anabolic and catabolic activities that are dependent on continuous versus intermittent delivery of the agent. ${ }^{61,62}$

Potential uses of LRAP include as a protector against local root resorption (e.g., idiopathic root resorption) and as a regulator of cell function during periodontal regeneration. Further studies defining the mechanisms of action and activity in vivo should help to clarify the significance and value of using such molecules in attempts to regenerate oral structures.

\section{ACKNOWLEDGMENTS}

The authors thank Dr. Z.A. Yuan, University of Pennsylvania, Philadelphia, Pennsylvania, for construction of LRAP expression vector; Dr. J. Simmer, University of Michigan, Ann Arbor, Michigan, for sending the pig LRAP cDNA; and Biora, Malmo, Sweden, for providing the enamel matrix derivative. The authors express their gratitude to the Center for Craniofacial Regeneration (CCR) at the University of Michigan School of Dentistry, and the core facilities at the University of Washington School of Dentistry. The present study was supported in part by fellowship grant 200029/01 0 from the Brazilian government (CNPq) (FB) and by NIH grants DE09532 (MJS), DE11089 (CWG), and DE13045 (MLS).

\section{REFERENCES}

1. Lynch S, Genco R, Marx R, eds. Tissue Engineering: Applications in Maxillofacial Surgery and Periodontics. Carol Stream, IL: Quintessence Publishing Company; 1999; 3-297.

2. Wikesjö UM, Selvig KA, eds. Periodontal wound healing and regeneration. Periodontol 2000 1997;19:7-172.

3. MacNeil RL, Somerman MJ. Development and regeneration of the periodontium: Parallels and contrasts. Periodontol 2000 2000;19:8-20.

4. Saygin N, Giannobile WV, Somerman MJ. Molecular and cell biology of cementum. Periodontol 2000 2000;24:73-98.

5. Thesleff I, Nieminen P. Tooth morphogenesis and cell differentiation. Curr Opin Cell Biol 1996;8:844-850.

6. Slavkin HC, Bringas P, Bessem C, et al. Hertwig's epithelial root sheath differentiation and initial cementum and bone formation during long-term organ culture of mouse mandibular first molars using serumless, chemicallydefined medium. J Periodontal Res 1989;24:28-40.

7. Fong CD, Slaby I, Hammarstrom L. Amelin: An enamelrelated protein, transcribed in the cells of epithelial root sheath. J Bone Miner Res 1996;11:892-898.

8. Hammarstrom L. Enamel matrix, cementum development and regeneration. J Clin Periodontol 1997;24:658-668.

9. Fukae M, Tanabe T, Yamakoshi Y, Yamada M, Ujie Y, Oida S. Immunoblot detection and expression of enamel proteins at the apical portion of the forming root in porcine permanent incisor tooth germs. J Bone Miner Metab 2001;19:236-243.
10. Hatakeyama J, Sreenath T, Hatakeyama Y, et al. RANKLmediated osteoclastogenesis pathway is elevated in amelogenin null mice. J Biol Chem 2003;278:35743-35748.

11. Gibson C, Yuan Z, Hall B. Amelogenin-deficient null mice display an amelogenesis imperfecta phenotype. J Biol Chem 2001;276:31871-31875.

12. Viswanathan HL, Berry JE, Foster BL, et al. Amelogenin: A potential regulator of cementum-associated genes. $J$ Periodontol 2003;74:1423-1431.

13. Goldberg HA, Warner KJ, Stillman MJ, Hunter GK. Determination of hydroxyapatite-nucleating region of bone sialoprotein. Connect Tiss Res 1996;35:385-392.

14. Ganss B, Kim RH, Sodek J. Bone sialoprotein. Crit Rev Oral Biol Med 1999;10:79-98.

15. Brookes SJ, Robinson C, Kirkham J, Bonass WA. Biochemistry and molecular biology of amelogenin proteins of developing dental enamel. Arch Oral Biol 1995;40: $1-14$.

16. Lindhe J. Emdogain. A biological approach to periodontal regeneration. J Clin Periodontol 1997;24:657-714.

17. Gestrelius S, Lyngstadaas SP, Hammarstrom L. Emdogainperiodontal regeneration based on biomimicry. Clin Oral Invest 2000;4:120-125.

18. Tokiyasu Y, Takata T, Saygin E, Somerman M. Enamel factors regulate expression of genes associated with cementoblasts. J Periodontol 2000;71:1829-1839.

19. Hakki S, Berry JE, Somerman MJ. The effect of enamel matrix protein derivative on follicle cells in vitro. JPeriodontol 2001;72:679-687.

20. Kawase T, Okuda K, Momose M, Kato Y, Yoshie H, Burns DM. Enamel matrix derivative (Emdogain) rapidly stimulates phosphorylation of the MAP kinase family and nuclear accumulation of smad2 in both oral epithelial and fibroblastic human cells. J Periodontal Res 2001;36:367-376.

21. Gestrelius S, Andersson C, Lidstrom D, Hammarstrom L, Somerman M. In vivo studies on periodontal ligament cells and enamel matrix derivative. J Clin Periodontol 1997; 24:685-692.

22. Yuan Z, Chen E, Gibson CW. Model system for evaluation of alternative splicing: Exon skipping. DNA Cell Biol 2001;20:807-813.

23. Veis A, Tompkins K, Alvares K, et al. Specific amelogenin splice products have signaling effects on cells in culture and in implants in vivo. J Biol Chem 2000;275:41263-41272.

24. Veis A. Amelogenin gene splice products: Potential signaling molecules. Cell Mol Life Sci 2003;60:38-55.

25. Tompkins K, Veis A. Polypeptides translated from alternative spliced transcripts from amelogenin gene, devoid of the exon $6 a, b, c$ region, have specific effects on tooth germ development in culture. Connect Tiss Res 2002;43: 224-231.

26. D'Errico JA, Berry JE, Ouyang H, Strayhorn CL, Windle $\mathrm{JJ}$, Somerman MJ. Employing a transgenic animal model to obtain cementoblasts in vitro. J Periodontol 2000;71: 63-72.

27. Chen D, Chen H, Feng JQ, et al. Osteoblastic cell lines derived from a transgenic mouse containing the osteocalcin promoter driving SV40 T-antigen. Mol Cell Differentiation 1995;3:193-212.

28. D'Errico JA, MacNeil RL, Takata T, Berry J, Strayhorn C, Somerman MJ. Expression of bone associated markers by tooth root lining cells in situ and in vitro. Bone 1997; 20:117-126.

29. Robinson C, Lowe NR, Weatherell JA. Amino acid composition, distribution and origin of "tuft" protein in the human and bovine dental enamel. Arch Oral Biol 1975; 20:29-42. 
30. Deutsch D, Palmon A, Fisher LW, Kolodny N, Termine JD, Young MF. Sequencing of bovine enamelin ("tuftelin") a novel acidic enamel protein. J Biol Chem 1991;266:1602116028.

31. Celeste AJ, Rosen V, Buecker JL, Kriz R, Wang EA, Wozney JM. Isolation of the human gene for bone protein utilizing mouse and rat cDNA clones. J EMBO 1986;5: 1885-1890.

32. Young MF, Kerr JM, Termine JD, et al. cDNA cloning, mRNA distribution and heterogeneity, chromosomal location, and RFLP analysis of human osteopontin (OPN). Genomics 1990;7:491-502.

33. Ducy P, Zhang R, Geoffroy V, Ridall AL, Karsenty G. Osf2/Cbfa1: A transcriptional activator of osteoblast differentiation. Cell 1997;89:747-754.

34. Kostenuik PJ, Shalhoub V. Osteoprotegerin: A physiological and pharmacological inhibitor of bone resorption. Curr Pharm Design 2001;7:613-635.

35. Theill LE, Boyle WJ, Penninger JM. RANK-L and RANK: T cells, bone loss, and mammalian evolution. Annu Rev Immunol 2002;20:795-823.

36. Ducy P. Cbfa1: A molecular switch in osteoblast biology. Develop Dynam 2000;219:461-471.

37. Pearson G, Robinson F, Gibson TB, et al. Mitogen-activated protein (MAP) kinase pathways: Regulation and physiological functions. Endocrine Rev 2001;22:153-183.

38. Kagayama M, Li HC, Zhu J, Sasano Y, Hatakeyama Y, Mizoguchi I. Expression of osteocalcin in cementoblasts forming acellular cementum. J Periodontal Res 1997;32: 273-278.

39. Bosshardt DD, Zalzal S, Mckee MD, Nanci A. Developmental appearance and distribution of bone sialoprotein and osteopontin in human and rat cementum. Anat Rec 1998;250:13-33.

40. Moradian-Oldak J. Amelogenins: Assembly, processing and control of crystal morphology. Matrix Biol 2001;20: 293-305.

41. Sculean A, Windish P, Keglevich T, Fabi B, Lundgren E, Lyngstadaas P. Presence of an enamel matrix protein derivative on human teeth following periodontal surgery. Clin Oral Invest 2002;6:183-187.

42. Hasegawa N, Kawaguchi H, Ogawa H, Uchida T, Kurihara $\mathrm{H}$. Immunohistochemical characteristics of epithelial cell rests of Malassez during cementum repair. J Periodont Res 2003;38:51-56.

43. Van der Pauw MT, Van der Bos T, Everts V, Beertsen W. Enamel matrix derivative protein stimulates attachment of periodontal ligament fibroblasts and enhances alkaline phosphatase activity and transforming growth factor- $\beta 1$ release of periodontal ligament and gingival fibroblasts. $J$ Periodontol 2000;71:31-43.

44. Diekwisch T, David S, Bringas P Jr, Santos V, Slavkin HC. Antisense inhibition of AMEL translation demonstrates supramolecular controls for enamel HAP crystal growth during embryonic mouse molar development. Development 1993;117:471-482.

45. Lyngstadaas SP, Risnes S, Sproat BS, Thrane PS, Prydz HP. A synthetic, chemically modified ribozyme eliminates amelogenin, the major translation product in developing mouse enamel in vivo. J EMBO 1995;14:5224-5229.

46. Bosshardt DD, Nanci A. Immunolocalization of epithelial and mesenchymal matrix constituents in association with inner enamel epithelial cells. J Histochem Cytochem 1998;46:135-142.
47. MacNeil RL, D’Errico JA, Ouyang H, Berry JE, Strayhorn C, Somerman MJ. Isolation of murine cementoblasts: Unique cells or uniquely-positioned osteoblasts. Eur J Oral Sci 1998;106:350-356.

48. Ducy P. Skeletal Gla proteins: Gene structure, regulation of expression, and function. In: Bilezikian JP, Raisz LG, Rodan GA, eds. Principles of Bone Biology. San Diego: Academic Press; 1996;183-196.

49. Fisher LW, Fedarko NS. Six genes expressed in bones and teeth encode the current members of the SIBLING family of proteins. Connect Tiss Res 2003;44:33-40.

50. Lian JB, Balint E, Javed A, et al. Runx1/AML1 hematopoietic transcription factor contributes to skeletal development in vivo. J Cell Physiol 2003;196:301-311.

51. Wise GE, Frazier-Bowers S, D'Souza RN. Cellular, molecular and genetic determinants of tooth eruption. Crit Rev Oral Biol Med 2002;13:323-334.

52. Hasegawa T, Yoshimura Y, Kikuiri T, et al. Expression of receptor activator of $\mathrm{NF} \kappa \mathrm{B}$ ligand and osteoprotegerin in culture of human periodontal ligament cells. J Periodont Res 2002;37:405-411.

53. Rani CS, Macdougall $M$. Dental cells express factors that regulate bone resorption. Mol Cell Biol Res Commun 2000;3:145-152.

54. MacNeil RL, Thomas HF. Development of the murine periodontium. I. Role of basement membrane in formation of mineralized tissue on the developing root dentin surface. J Periodontol 1993;64:95-102.

55. Hu CC, Fukae M, Uchida T, et al. Sheathlin: Cloning, cDNA/polypeptide sequences, and immunolocalization of porcine enamel sheath proteins. J Dent Res 1997;76: 648-657.

56. Krebsbach PH, Lee SK, Matsuki Y, Kozak CA, Yamada KM, Yamada Y. Full-length sequence, localization, and chromosomal mapping of ameloblastin-a novel tooth-specific gene. J Biol Chem 1996;271:4431-4435.

57. Bosshardt DD, Nanci A. Immunodetection of enamel- and cementum-related (bone) proteins at the enamel-free area and cervical portion of the tooth in rat molars. $J$ Bone Miner Res 1997;12:367-379.

58. Bosshardt DD, Selvig KA. Dental cementum: The dynamic tissue covering of the root. Periodontol 2000 1997;13:41-75.

59. Paine ML, Wang HJ, Luo W, Krebsbach PH, Snead ML. A transgenic animal model resembling amelogenesis imperfecta related to ameloblastin overexpression. J Biol Chem 2003;278:19447-19452.

60. Diekwish TG. The developmental biology of cementum. Int J Deu Biol 2001;45:695-706.

61. Neer RM, Arnaud CD, Zanchetta JR, et al. Effect of parathyroid hormone (1-34) on fractures and bone mineral density in postmenopausal women with osteoporosis. N Engl J Med 2001;344:1434-1441.

62. Horwitz MJ, Tedesco MB, Gundberg C, Garcia-Ocana A, Stewart AF. Short-term, high-dose parathyroid hormonerelated protein as a skeletal anabolic agent for the treatment of postmenopausal osteoporosis. J Clin Endocrinol Metab 2003;88:569-575.

Correspondence: Dr. Martha J. Somerman, 1959 NE PacificD322-Health Science Center, University of Washington, Seattle, WA 98195-7444. Fax: 206/616-7478; e-mail: somerman@ u.washington.edu.

Accepted for publication January 4, 2004. 